\title{
Sales Effort and Coordination in an 020 Supply Chain with Two-Period of Marketing
}

\author{
Jing Shi \\ School of Economics \& Management, Shanghai Maritime University, Shanghai, China \\ Email: jingshi@shmtu.edu.cn
}

How to cite this paper: Shi, J. (2020). Sales Effort and Coordination in an O2O Supply Chain with Two-Period of Marketing. Open Journal of Business and Management, 8, 1020-1033.

https://doi.org/10.4236/ojbm.2020.83065

Received: February 12, 2020

Accepted: April 7, 2020

Published: April 10, 2020

Copyright $\odot 2020$ by author(s) and Scientific Research Publishing Inc. This work is licensed under the Creative Commons Attribution International License (CC BY 4.0).

http://creativecommons.org/licenses/by/4.0/

\section{(c) (i) Open Access}

\begin{abstract}
$\mathrm{O} 2 \mathrm{O}$ supply chain has been a hot issue worldwide in recent years. This paper studies a two-period marketing problem in an $\mathrm{O} 2 \mathrm{O}$ supply chain consisting of a manufacturer and an offline retailer. Besides the offline channel, the manufacturer owns an online channel which markets to the online customers and directs potential customers to the offline retailer. The retailer provides service for both the offline customers and the directed customers from online channel. The centralized and decentralized settings are both analyzed. The sales effort level of the retailer is higher than that of the manufacturer under centralized setting. The service levels of both retailer and manufacturer and supply chain profit under the decentralized setting are lower than that of the centralized setting. This paper finds that a two-way subsidy contract can fully coordinate the supply chain.
\end{abstract}

\section{Keywords}

O2O, Supply Chain, Sales Effort, Coordination, Contract, Two-Period Marketing

\section{Introduction}

$\mathrm{O} 2 \mathrm{O}$ (online-to-offline) has changed many traditional industries. Many $\mathrm{O} 2 \mathrm{O}$ platforms provide information, product and service to online customers and then direct them to offline business partners. For example, many sellers sell products or services on App Meituan, one of the biggest O2O platform in China. The online customer can place the order online and then visit the brick-and-mortar store (Li et al., 2017). At the same time, the offline customer can place order at the store. This kind of business is commonly seen in practice and has been studied a lot in literature. However, there is another kind of $\mathrm{O} 2 \mathrm{O}$ business model.

This research is motivated by the practice in furniture industry. Nowadays, 
more and more people choose customized furniture which can utilize the space effectively. Many customized furniture brands arise, such as Suofeiya, Oppein, and Shangpin Home Collection etc. Different customers have different requirements of designs. They need to communicate with the designer for many times. Thus, most of them have offline channels. Some of them operate in a centralized model and some of them operate in a decentralized model. In the era of mobile Internet, more and more manufacturers try to exploit the benefit of Internet. For instance, Shangpin Home Collection is one of the make-to-order furniture manufacturers in China who operates in an $\mathrm{O} 2 \mathrm{O}$ environment. This company sells products mainly through offline franchisees. Besides offline channel, it owns an online channel. The online channel can provide the price and style information to customers. However, customers usually do not place orders online directly because they need the help of the designer to give the specific design. That is to say, there is two-period of marketing for the online customer. At the first period, the online customers can get information from the online channel of the manufacturer. Then the potential customer is directed to the nearest offline franchisee. The designer of the offline franchisee then measures the size of the customer's home and presents suitable designs for them. Then the customer decides whether to place the order.

During the two-period of marketing, the sales effort of the manufacturer such as advertisement and the service provided by the franchisee is critical to enhance the demand of online channel. The retailer's service effort can influence the customer directed by the manufacturer. That is, the sales effort of the retailer is performed after the sales effort of the manufacturer. Besides, the sales effort of the offline retailer also impacts the demand of the offline channel. This two-period of marketing in $\mathrm{O} 2 \mathrm{O}$ channel has not been studied as so far. The interaction between the manufacturer and the offline retailer is an interesting issue. What is the optimal service level of the manufacturer and the offline retailer? How to stimulate each other to maximize the overall profit of the supply chain?

Usually, the profit of the decentralized supply chain is lower than the centralized setting (Dellarocas, 2012). In order to maximize the profit of the whole supply chain, many coordination contracts are studied in literature, such as buy back contract, wholesale price contract, revenue sharing contract etc. (Cachon \& Lariviere, 2005). In this study, these questions will be explored: Whether the profit of the centralized setting is higher than that of the decentralized setting? What is the optimal contract to coordinate the supply chain to maximize the overall profit?

This paper studies a supply chain consisting of one manufacturer and one retailer. The manufacturer sells product through the retailer to offline customers. Besides, the manufacturer owns an online channel which provides the information about price and designs to online customers. At the same time, the manufacturer advertises on many platforms such as WeChat. The online customers 
cannot place orders directly and they are directed to the offline retailer. The retailer provides services for them, such as designs of furniture. Then the customer decides whether to place the order.

The reminder of this paper is organized as follows. Section 2 presents a literature review. Section 3 describes the basic model. In Section 4, the equilibriums under centralized setting and decentralized setting are analyzed and numerical examples are used to illustrate the results. A two-way coordination mechanism is given in Section 5. This paper concludes in Section 6 with a discussion of implications and research directions.

\section{Literature Review}

This study relates to $\mathrm{O} 2 \mathrm{O}$ channel, sales effort and supply chain coordination. Related literature is reviewed as follows.

\subsection{Channel}

Many studies on $\mathrm{O} 2 \mathrm{O}$ channel focus on dual channel who sells identical products or services and customers can place orders in either channel. Li et al. (2017) studies the cooperative advertising strategies in an $\mathrm{O} 2 \mathrm{O}$ supply chain consisting of a seller and an online platform agent. The offline seller sells directly through brick and mortar stores and sells online through a platform agent. The customer can buy the product or service online or offline because the product or service is identical in both channels. The online demand is dependent on the advertising level of the seller and the platform simultaneously. Yan \& Pei (2018) studies the return policies under the manufacturer-traditional retailer supply chain where the manufacturer opens an online channel to compete with the traditional retailer. Chen (2015) studies a two-echelon supply chain consisting of an offline retailer and a manufacturer. The retailer determines the retail price and the level of local advertising, and the manufacturer promotes the product's national brand. The manufacturer decides to sell online. The price schemes and cooperative advertising mechanisms on dual-channel supply chain competition are investigated.

Some studies consider the interaction between online channel and offline channel operations. Gao \& Su (2017) studies the impact of the BOPS (Buy online and pick up in store) initiative on a retailer's operations. They find that not all products are well suited for in-store pickup. They develop a theoretical model to study the impact of self-order technologies on customer demand, employment levels and profits of restaurants who sells orders through online and offline channels. David et al. (2018) studies the impact of introduction of showrooms (physical locations where customers can view and try products) in combination with online fulfillment on demand generation and operational efficiency. They find that showrooms increase demand overall and in the online channel as well. Showrooms improve overall operational efficiency by increasing conversion in a sampling channel and by decreasing returns. Santiago et al. (2017) investigates 
the cross-channel functionalities which allows customers to ship products to their local store free of charge when those products are not available in their local store. They study the effects of the introduction of cross-channel functionalities on the overall sales dispersion of retailers and the implication of these effects for inventory management.

\subsection{Sales Effort}

Sales effort is very important in attracting customers not only in online but also in offline. For online sellers, the advertising effort is crucial. For offline retailers, physical store assistance has a positive impact on customer satisfactory (Parasuraman et al., 1988; Heskett et al., 2008) and can influence demand (Taylor, 2002). Ofek et al. (2011) considers the impact of physical store assistance on product returns and demand.

Many studies about sales effort in dual-channel assume that the demand is influenced by the service level of the manufacturer and the retailer simultaneously. For example, Li et al. (2017) studies the cooperative advertising problem in $\mathrm{O} 2 \mathrm{O}$ supply chains where the demand of both channels is simultaneously influenced by the advertising levels of the seller and the O2O platform. Xie et al. (2017) considers the manufacturer and the retailer advertise together and share the cost of advertising.

Some research studies the free riding problem in dual-channels, in which pre-sales services can be conducted separately from the actual sale of the products (Shin, 2007; Kucuk \& Maddux, 2010). The pre-sales services can be conducted separately from the actual sale of the products, such as clothes, shoes, toys and furniture, etc. Zhou et al. (2018) considers a supply chain sells products through both online channel and a traditional retailer. The manufacturer's online channel free-rides the retailer's presales services. In this paper, free-riding does not exist because the customer cannot place order online directly. However, the manufacturer charges a portion of the revenue generated from the customers attracted through online channel, which may decrease the incentive of the retailer to provide higher sales effort.

\subsection{Supply Chain Coordination}

To avoid double marginalization effect, various contracts are designed to coordinate the supply chain. There are some classical contracts, such as buy-back/markdown contracts (Chen \& Bell, 2011), target rebate contract (Taylor, 2002; Ferguson et al., 2006), quantity discount contract (Raju \& Zhang, 2005), revenue-sharing contract (Cachon \& Lariviere, 2005), quantity-flexibility contract (Tsay \& Agrawal, 2000), two-part tariffs (Lau et al., 2008) and subsidy contract (Xiao et al., 2009). Readers can refer to Cachon \& Lariviere (2005) for a review of supply chain contracts.

This paper relates to revenue sharing mechanism and subsidy mechanism. Cachon \& Lariviere (2005) find that revenue-sharing contracts can coordinate 
the supply chain. Xu et al. (2014) establish a dual-channel supply chain coordinating contract, which consists of a two-way revenue sharing contract. Manufacturer gets a fraction of the revenue generated by retailer's channel in the traditional revenue sharing contract, while retailer gets a fraction of the revenue generated by manufacturer's direct channel in the reverse revenue sharing contract.

Sales effort can enhance the demand. However, investment in sales effort incurs cost. The retailer makes a trade-off between the benefit and the cost. In order to encourage the retailer to provide higher sales effort, the manufacturer may provide subsidy to the retailer to share the cost of sales effort. Wang \& Gerchak (2001) study the coordination problem of a supply chain when demand is shelf-space dependent. The manufacturer provides a subsidy to the retailer to share the inventory cost of displayed products. Xiao et al. (2005) design a price-subsidy rate contract to coordinate the promotion investments of the competing retailers under demand disruptions.

\subsection{Research Gap}

In the above studies, the customers can place the order online directly. However, none of them has studied the two-period marketing phenomenon in $\mathrm{O} 2 \mathrm{O}$ channel where customers do not place orders online directly. They need the service of offline stores. For example, in the make-to-order furniture industry, online customers can get information online and then be directed to the offline stores. Customers decide whether to place the order after the brick-and-mortar store shows the designs. This paper fills this gap by exploring the interaction between a manufacturer and an offline retailer who provides service in brick-and-mortar store. Besides, the manufacturer operates an online channel which attracts customers and directs them to the offline retailer. Then, the retailer provides sales service to the potential customers. That is, there exists two-period of marketing.

However, none of them has considered the two-period setting where the retailer's effort can only influence the portion of online customers directed by the manufacturer. That is, the sales effort of the retailer is performed after the sales effort of the manufacturer.

\section{Basic Model}

This paper studies a supply chain consisting of one manufacturer and one retailer. The manufacturer owns an offline channel which sells product through independent retailer and an online channel which tries to attract online customers and direct them to the offline retailer. The number of attracted online customers depends on the marketing sales effort of the manufacturer which is denoted by $s_{M} \in(0,1)$. How many of them will finally buy depends on the sales service level of the offline retailer which is denoted by $s_{R} \in(0,1)$. The offline demand also depends on the sales effort of the retailer. The supply chain operates in a make-to-order environment. The retailer acts as an intermediary between cus- 
tomers and the manufacturer. The retailer provides services for customers, such as design services. After the customer places the order, the retailer transforms the order to the manufacturer. The service effort of the retailer is very important to attract the customer to place the order. The supply chain structure is shown in Figure 1.

There are two periods of marketing for the manufacturer's online channel. At the first period, some online customers are attracted by the manufacturer, and then are directed to the offline retailer by the manufacturer. At the second period, the customer visits the nearest retail store to get the details of the product and the retailer provides services for them such as design services. Some customers may place orders at the retail store and some may just leave. At the second period, the final demand depends solely on the service effort of the offline retailer. Thus, the manufacturer has an incentive to encourage the retailer to provide higher sales effort. The manufacturer charges the retailer a portion of profit generated from the customers who are directed to the retailer. This action may have a negative effect on the retailer's incentive to provide higher sales effort.

Similar to Taylor (2002), a multiplicative demand function of sales effort is adopted. Assume that the basic demand of offline channel and online channel are $a$ and $a_{d}$, respectively. Thus, the demand of offline channel is $D_{0}=a s_{R}$, the potential demand attracted by the manufacturer is $D_{d}=a_{d} s_{M}$. The final demand of online channel then is determined by the offline retailer's sales effort. The best situation is that all the customers attracted by the manufacturer's online channel place orders. The worst case is that none of them place orders at the offline retailer. For the offline retailer, the potential demand from online is $D_{d}=a_{d} s_{M}$, thus, the final demand of the retailer is $D_{d} \cdot s_{R}=a_{d} s_{M} s_{R}$.

The total demand will be

$$
D=a s_{R}+a_{d} s_{M} s_{R}
$$

Assume that the profit margin of each product is $m$. The retailer takes a fraction $m \varphi \in(0,1)$ of the marginal profit and the manufacturer takes a fraction

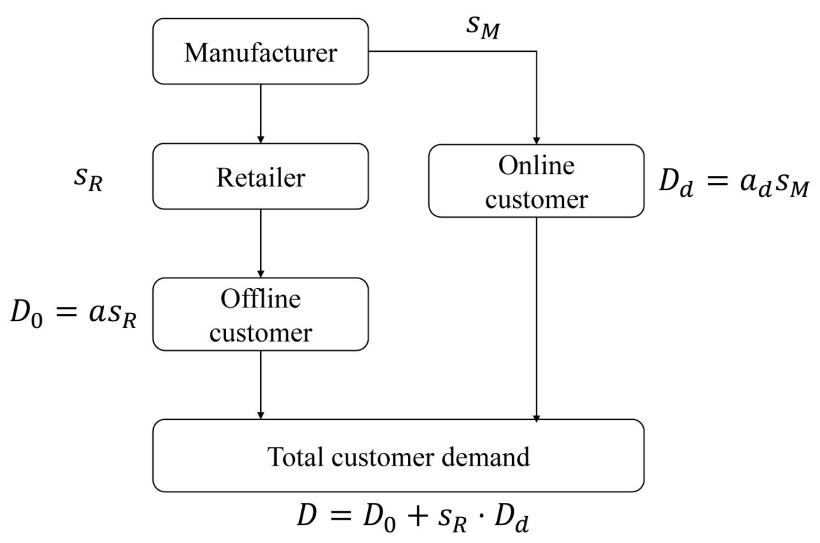

Figure 1. Supply chain structure. 
$(1-\varphi)$. The profit margin and revenue sharing rate are assumed exogenously given since the main focus of this study is sales effort of both members. For the marginal profit generated through online channel, the manufacturer charges a proportion of $\sigma$. The manufacturer and the offline retailer need to decide the online sales effort and the offline service effort, respectively. Following Ofek et al. (2011), the cost to provide the sales effort $s_{R}$ is $\eta s_{R}^{2} / 2$ and the cost to provide the sales effort is $\eta s_{M}^{2} / 2$, where $\eta$ is the sales effort cost factor.

The profit of the manufacturer is

$$
\pi_{M}=(1-\varphi) m D-\eta s_{M}^{2} / 2+\sigma m s_{R} D_{d}
$$

The profit of the retailer is

$$
\pi_{R}=\varphi m D-\eta s_{R}^{2} / 2-\sigma m s_{R} D_{d}
$$

In this game, the manufacturer and the retailer decide sales effort simultaneously. Note that in this paper, price is not considered since the major focus of this paper is the interaction between the sales effort of the supply chain members. This kind of assumption is not uncommon in literature, such as Li et al. (2017). The competition in furniture industry is very fierce in China. The products have little differentiation and the prices are relatively similar. Thus, the price of the product can be viewed as exogenously given. One of the furniture companies in china, Shangpin Home Collection, states that the price of the product is almost equal to cost plus profit margin. The cost is decided by market. As a result, it is reasonable to assume that the profit margin is exogenously given. In the market, it is the sales effort that determines the demand of the product.

\section{Equilibrium}

\subsection{Centralized Setting}

As a benchmark, the centralized setting is explored. In the centralized setting, the integrated supply chain decides the online and offline sales effort simultaneously. The profit of the whole supply chain is

$$
\pi_{C}=m D-\eta s_{R}^{2} / 2-\eta s_{M}^{2} / 2
$$

Proposition 1 shows the optimal online and offline sales effort of the manufacturer and the retailer, respectively.

Proposition 1. When $\eta>a_{d} m$ and $a<\min \left\{\left[\eta^{2}-\left(a_{d} m\right)^{2}\right] /\left(m^{2} a_{d}\right),\left[\eta^{2}-\left(a_{d} m\right)^{2}\right] /(m \eta)\right\}$, under centralized setting, the optimal sales effort for the retailer and the manufacturer are $s_{R}^{C *}=a m \eta /\left[\eta^{2}-\left(a_{d} m\right)^{2}\right]$ and $s_{M}^{C *}=a m^{2} a_{d} /\left[\eta^{2}-\left(a_{d} m\right)^{2}\right]$, respectively. The profit of the whole supply chain is $\pi_{C}^{*}=a^{2} m^{2} \eta /\left[2 \eta^{2}-2\left(a_{d} m\right)^{2}\right]$.

Proof: Since $\partial^{2} \pi_{C} / \partial s_{R}^{2}=-\eta<0, \partial^{2} \pi_{C} / \partial s_{M}^{2}=-\eta$ and $\partial^{2} \pi_{C} / \partial s_{R} \partial s_{M}=a_{d} m$. Only when $\eta^{2}-\left(a_{d} m\right)^{2}>0, \pi_{C}$ is a concave function over $\left(s_{R}, s_{M}\right)$. Thus, $\eta>a_{d} m$ must be satisfied since $\eta>0$. 
The first-order conditions are $\partial \pi_{C} / \partial s_{R}=m\left(a+a_{d} s_{M}\right)-s_{R} \eta=0$ and $\partial \pi_{C} / \partial s_{M}=a_{d} m s_{R}-s_{M} \eta=0$, respectively. By solving the first-order conditions together, the optimal sales effort of online and offline are $s_{R}^{C *}=a m \eta /\left[\eta^{2}-\left(a_{d} m\right)^{2}\right]$ and $s_{M}^{C *}=a m^{2} a_{d} /\left[\eta^{2}-\left(a_{d} m\right)^{2}\right]$, respectively. From $s_{M}^{C *} \in(0,1)$ and $s_{R}^{C *} \in(0,1)$, the conditions $s_{R}^{C *}=a m \eta /\left[\eta^{2}-\left(a_{d} m\right)^{2}\right]<1$ and $s_{M}^{C *}=a m^{2} a_{d} /\left[\eta^{2}-\left(a_{d} m\right)^{2}\right]<1$ must be satisfied. That is $a<\min \left\{\left[\eta^{2}-\left(a_{d} m\right)^{2}\right] /\left(m^{2} a_{d}\right),\left[\eta^{2}-\left(a_{d} m\right)^{2}\right] /(m \eta)\right\}$. Then the maximum profit of the centralized supply chain is derived as $\pi_{C}^{*}=a^{2} m^{2} \eta /\left[2 \eta^{2}-2\left(a_{d} m\right)^{2}\right]$

From Proposition 1, $\eta>a_{d} m$, then corollary 1 is derived as follows.

Corollary 1. $S_{R}^{C *}>s_{M}^{C *}$.

Corollary 1 shows that the sales effort level of the retailer is higher than that of the manufacturer under centralized setting. The reason may be that the retailer's sales effort influences the potential demand from both online and offline. The manufacturer's sales effort can only influence online customers. The retailer has more incentive to provide higher sales effort.

\subsection{Decentralized Setting}

In this section, a decentralized setting is analyzed. The manufacturer and the retailer are independent entities and optimize their profits simultaneously. The equilibriums are derived as following.

Proposition 2. When $M>0$ and $a<\min \left\{M /(m \eta \varphi), M /\left[m^{2} a_{d} \varphi(1-\varphi+\sigma)\right]\right\}$, under the decentralized setting, the equilibrium sales effort for the retailer and the manufacturer are $s_{R}^{*}=\operatorname{am\eta } \varphi / M$ and $s_{M}^{*}=a m^{2} a_{d} \varphi(1+\sigma-\varphi) / M$, respectively, where $M=\eta^{2}+a_{d}^{2} m^{2}\left[\sigma+\sigma^{2}-2 \sigma \varphi-(1-\varphi) \varphi\right]$. The profit of the retailer is $\pi_{R}^{*}=a^{2} m^{2} \eta^{3} \varphi^{2} / G$. The profit of the manufacturer is $\pi_{M}^{*}=a^{2} m^{2} \eta \varphi\left\{2 \eta^{2}(1-\varphi)+\left(a_{d} m\right)^{2}(1-\varphi+\sigma)\left[\sigma(2-\varphi)-\varphi+\varphi^{2}\right]\right\} / G$. The profit of the total supply chain is

$$
\pi_{T}^{*}=a^{2} m^{2} \eta \varphi\left\{\eta^{2}(2-\varphi)+\left(a_{d} m\right)^{2}(1-\varphi+\sigma)\left[\sigma(2-\varphi)-\varphi+\varphi^{2}\right]\right\} / G
$$

where $G=2\left[\eta^{2}+\left(a_{d} m\right)^{2}(\sigma-\varphi)(1-\varphi+\sigma)\right]^{2}$.

Proof: Since $\partial^{2} \pi_{M} / \partial s_{M}^{2}=-\eta<0, \partial^{2} \pi_{R} / \partial s_{R}^{2}=-\eta$, both $\pi_{M}$ and $\pi_{R}$ are concave functions. The first-order conditions are

$$
\partial \pi_{R} / \partial s_{R}=-s_{R} \eta+m\left[a \varphi+a_{d} s_{M}(\varphi-\sigma)\right]=0
$$

and

$$
\partial \pi_{M} / \partial s_{M}=-s_{M} \eta+a_{d} m s_{R}(1+\sigma-\varphi)=0 .
$$

By solving the first-order conditions together, the optimal sales effort online and offline are $s_{R}^{*}=a m \eta \varphi /\left\{\eta^{2}+a_{d}^{2} m^{2}\left[\sigma+\sigma^{2}-2 \sigma \varphi-(1-\varphi) \varphi\right]\right\}$ and 
$s_{M}^{*}=a m^{2} a_{d} \varphi(1-\varphi+\sigma) /\left\{\eta^{2}+a_{d}^{2} m^{2}\left[\sigma+\sigma^{2}-2 \sigma \varphi-(1-\varphi) \varphi\right]\right\}$, respectively. Let $M=\eta^{2}+a_{d}^{2} m^{2}\left[\sigma+\sigma^{2}-2 \sigma \varphi-(1-\varphi) \varphi\right]$. Note that $s_{M}^{*} \in(0,1)$ and $s_{R}^{*} \in(0,1)$ must be satisfied. That is $M>0$ and

$a<\min \left\{M /(m \eta \varphi), M /\left[m^{2} a_{d} \varphi(1-\varphi+\sigma)\right]\right\}$. Then the profits of the manufacturer and the retailer can be derived.

Numerical examples are showed below to illustrate the results in centralized setting and in decentralized setting. The default values of the parameters are used as follows: $a=80 ; a_{d}=100 ; m=5 ; \varphi=0.6 ; \sigma=0.4$. The values of these parameters ensure that the equilibrium exists and the service levels are in the interval $(0,1)$.

Figure 2 shows the service level of the retailer versus the sales effort cost factor in centralized and decentralized settings. The thin curve denotes the service level of the retailer under centralized setting, whereas the thick curve denotes service level of the retailer under decentralized setting. It shows that the service level of the retailer under decentralized setting is lower than that of the centralized setting. The service level of the retailer under both settings decreases with the sales effort cost factor. Figure 3 shows the service level of the manufacturer versus the sales effort cost factor under centralized and decentralized settings. The results are similar with that of the retailer. Figure 2 and Figure 3 demonstrate that the decentralization of the supply chain lowers the service levels of both members. Figure 4 illustrates the profit of the supply chain under centralized and decentralized setting. It shows that the profit of the supply chain under

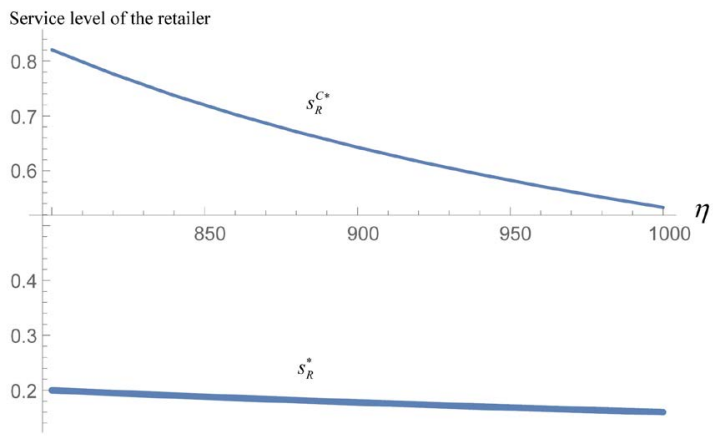

Figure 2. The service level of the retailer versus the sales effort cost factor.

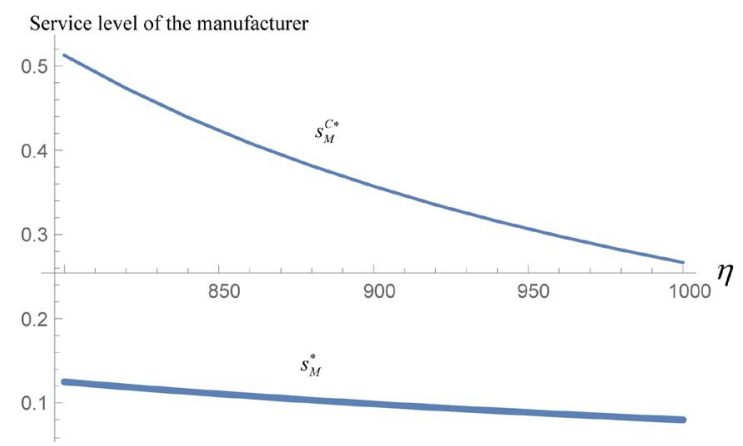

Figure 3. The service level of the manufacturer versus the sales effort cost factor. 


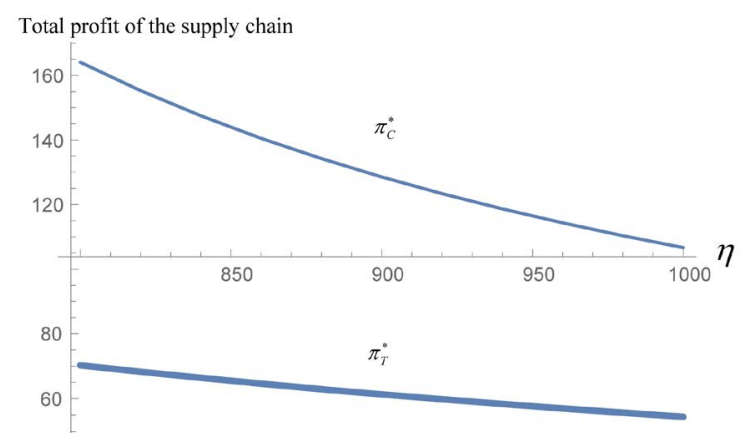

Figure 4. The total profit of the supply chain versus the sales effort cost factor.

decentralized setting is lower than that of the centralized setting. As a result, the supply chain needs coordination to maximize the profit of the whole supply chain. In next section, a coordination mechanism is explored to coordinate the supply chain.

\section{Coordination Mechanism}

In Section 4, the numerical illustration shows that the profit of the whole supply chain under decentralized setting is lower than that under centralized setting. In order to enhance the profit of the supply chain, supply chain coordination mechanism can be implemented. Similar to Song et al. (2017), the supply chain needs to coordinate the sales effort of the manufacturer and the retailer. Thus, a two-way subsidy contract is designed to coordinate the supply chain. Assume that the manufacturer undertakes $t$ proportion of the retailer's service effort cost $t \eta s_{R}^{2} / 2$ and the retailer undertakes $(1-t) \eta s_{R}^{2} / 2$. At the same time, the retailer provides a subsidy for the manufacturer's sales effort. The retailer undertakes $k$ proportion of the manufacturer's sales effort cost which is $k \eta s_{M}^{2} / 2$ and the manufacturer undertakes $(1-k) \eta s_{M}^{2} / 2$.

Under two-way subsidy policy, the profit of the manufacturer is

$$
\tilde{\pi}_{M}=(1-\varphi) m D-(1-k) \eta s_{M}^{2} / 2+\sigma m s_{R} a_{d} s_{M}-t \eta s_{R}^{2} / 2
$$

The profit of the retailer is

$$
\tilde{\pi}_{R}=\varphi m D-(1-t) \eta s_{R}^{2} / 2-\sigma m s_{R} a_{d} s_{M}-k \eta s_{M}^{2} / 2
$$

Proposition 3. A two-way subsidy contract can fully coordinate the supply chain. The manufacturer undertakes $t$ proportion of retailer's sales effort cost, and the retailer undertakes $k$ proportion of the manufacturer's sales effort cost, where $k=\varphi-\sigma$ and $t=1-\varphi+\left(a_{d} m\right)^{2} \sigma / \eta^{2}$.

Proof: Because $\mathrm{d}^{2} \tilde{\pi}_{R} / \mathrm{ds}_{R}^{2}=-(1-t) \eta<0$ and $\mathrm{d}^{2} \tilde{\pi}_{M} / \mathrm{ds} s_{M}^{2}=-(1-k) \eta<0$, $\tilde{\pi}_{R}$ and $\tilde{\pi}_{M}$ are both concave functions. The first-order conditions are as follows.

$$
\begin{gathered}
\mathrm{d} \tilde{\pi}_{M} / \mathrm{d} s_{M}=-(1-k) s_{M} \eta+a_{d} m s_{R}(1+\sigma-\varphi)=0 \\
\mathrm{~d} \tilde{\pi}_{R} / \mathrm{d} s_{R}=-s_{R}(1-t) \eta+m\left[a \varphi+a_{d} s_{M}(\varphi-\sigma)\right]=0
\end{gathered}
$$


By solving the first-order conditions together, the equilibrium results are

$$
\tilde{s}_{R}^{*}=a(1-k) m \eta \varphi /\left\{(1-k)(1-t) \eta^{2}+\left(a_{d} m\right)^{2}\left[\sigma+\sigma^{2}-2 \sigma \varphi-(1-\varphi) \varphi\right]\right\}
$$

and

$$
\tilde{s}_{M}^{*}=a m^{2} a_{d} \varphi(1-\varphi+\sigma) /\left\{(1-k)(1-t) \eta^{2}+\left(a_{d} m\right)^{2}\left[\sigma+\sigma^{2}-2 \sigma \varphi-(1-\varphi) \varphi\right]\right\} .
$$

In order to coordinate the supply chain, the sales effort under the contract must be equal to that under centralized setting. Thus, let $s_{R}^{C *}=\tilde{s}_{R}^{*}, s_{M}^{C *}=\tilde{s}_{M}^{*}$, the conditions can be derived as $t=1-\varphi+\left(a_{d} m\right)^{2} \sigma / \eta^{2}$ and $k=\varphi-\sigma$.

Proposition 3 shows that the decentralized supply chain can be fully coordinated by a two-way subsidy contract. In coordinated setting, the decentralized supply chain can achieve the profit under the centralized setting.

\section{Conclusion}

This paper studies a two-period marketing problem in an $\mathrm{O} 2 \mathrm{O}$ supply chain consisting of a manufacturer and an offline retailer. The manufacturer owns an online channel which markets to the online customers and directs potential customers to the offline retailer. Then the retailer provides services for the potential online customers. Besides, the retailer also provides services for offline customers. The service effort of the retailer influences both the demand of online and offline.

This paper firstly analyzed the centralized setting where the manufacturer and the retailer aim to maximize the overall profit of the supply chain. Then the decentralized setting is investigated. The results show that the service level of the retailer is higher than that of the manufacturer under centralized setting. $\mathrm{Nu}$ merical examples illustrate that the service levels of both retailer and manufacturer under decentralized setting is lower than that of the centralized setting. The profit of the whole supply chain under decentralized setting is lower than that under centralized setting. That is, the decentralization of the supply chain decreases the service levels and profit of the supply chain. Then, a two-way subsidy contract is designed to coordinate the supply chain. The result shows that a two-way subsidy contract can fully coordinate the supply chain. The sales effort of two members can reach the levels under the centralized setting. This paper contributes to the literature as follows. Firstly, this paper studies a novel O2O supply chain which has two-period marketing problem, where the manufacturer builds an online channel which directs potential customer to the offline retailer. The sales effort of the manufacturer influences the demand of potential customer online. Then the potential customers are directed to the offline retailer who influences the purchases of these customers. The final demand coming from online channel depends on both parties' sales effort. Secondly, this paper builds game models to describe the optimization problems of the supply chain under centralized and decentralized settings. Thirdly, this paper designs a useful coordination mechanism to maximize the profit of the whole supply chain which can 
be used in practice.

There are some interesting issues to study in the future. Firstly, this paper studies a supply chain consisting of a manufacturer and a retailer. The manufacturer sells to the retailer and at the same time operates an online website which directs potential customers to the offline retailer. The competition between supply chains hasn't studied in this paper. In the future, we can add another supply chain which competes with this supply chain. It would be interesting to study the decisions of supply chain members under supply chain competition. Secondly, this paper only considers the case that the potential online customer can be directed to the offline retailer. However, more and more people are using mobile phones. If you use mobile phone, it's inevitable to avoid advertisement. For example, WeChat is a very popular App in China. WeChat promotes advertisements. Thus, if the manufacturer advertises on WeChat, some offline potential customers may transfer to online website and then can be directed to the offline retailer. This phenomenon can complicate the model.

\section{Acknowledgements}

This research was supported by the National Natural Science Foundation of China [71601111].

\section{Conflicts of Interest}

The author declares no conflicts of interest regarding the publication of this paper.

\section{References}

Cachon, G. P., \& Lariviere, M. A. (2005). Supply Chain Coordination with Revenue-Sharing Contracts: Strengths and Limitations. Management Science, 51, 30-44.

https://doi.org/10.1287/mnsc.1040.0215

Chen, J., \& Bell, P. C. (2011). Coordinating a Decentralized Supply Chain with Customer Returns and Price-Dependent Stochastic Demand Using a Buyback Policy. European Journal of Operational Research, 212, 293-300. https://doi.org/10.1016/j.ejor.2011.01.036

Chen, T. H. (2015). Effects of the Pricing and Cooperative Advertising Policies in a Two-Echelon Dual-Channel Supply Chain. Computers \& Industrial Engineering, 87, 250-259. https://doi.org/10.1016/j.cie.2015.05.013

David, R. B., Santiago, G., \& Antonio, M. (2018). Offline Showrooms in Omnichannel Retail: Demand and Operational Benefits. Management Science, 64, 1629-1651. https://doi.org/10.1287/mnsc.2016.2684

Dellarocas, C. (2012). Double Marginalization in Performance-Based Advertising: Implications and Solutions. Management Science, 58, 1178-1195. https://doi.org/10.1287/mnsc.1110.1474

Ferguson, M., Guide, V. D. R., \& Souza, G. C. (2006). Supply Chain Coordination for False Failure Returns. Manufacturing \& Service Operations Management, 8, 376-393. https://doi.org/10.1287/msom.1060.0112

Gao, F., \& Su, X. (2017). Omnichannel Service Operations with Online and Offline 
Self-Order Technologies. Management Science, 64, 3595-3608.

https://doi.org/10.1287/mnsc.2017.2787

Heskett, J. L., Jones, T. O., Loveman, G. W., Sasser, W. E., \& Schlesinger, L. A. (2008). Putting the Service-Profit Chain to Work. Harvard Business Review, 86, 118-129.

Kucuk, S. U., \& Maddux, R. C. (2010). The Role of the Internet on Free-Riding: An Exploratory Study of the Wallpaper Industry. Journal of Retailing and Consumer Services, 17, 313-320. https://doi.org/10.1016/j.jretconser.2010.03.003

Lau, A. H. L., Lau, H. S., \& Wang, J. C. (2008). How a Dominant Retailer Might Design a Purchase Contract for a Newsvendor-Type Product with Price-Sensitive Demand. European Journal of Operational Research, 190, 443-458. https://doi.org/10.1016/j.ejor.2007.06.042

Li, X., Li, Y. J., \& Cao, W. J. (2017). Cooperative Advertising Models in O2O Supply Chains. International Journal of Production Economics, 215, 144-152. https://doi.org/10.1016/j.ijpe.2017.09.018

Ofek, E., Katona, Z., \& Sarvary, M. (2011). "Bricks and Clicks": The Impact of Product Returns on the Strategies of Multichannel Retailers. Marketing Science, 30, 42-60. https://doi.org/10.1287/mksc.1100.0588

Parasuraman, A., Zeithaml, V. A., \& Berry, L. L. (1988). SERVQUAL: A Multiple-Item Scale for Measuring Consumer Perceptions of Service Quality. Journal of Retailing, 64, $12-40$.

Raju, J., \& Zhang, Z. J. (2005). Channel Coordination in the Presence of a Dominant Retailer. Marketing Science, 24, 254-262. https://doi.org/10.1287/mksc.1040.0081

Santiago, G., Antonio, M., \& Loannis, S. (2017). Channel Integration, Sales Dispersion, and Inventory Management. Management Science, 63, 2813-2831. https://doi.org/10.1287/mnsc.2016.2479

Shin, J. (2007). How Does Free Riding on Customer Service Affect Competition? Marketing Science, 26, 488-503. https://doi.org/10.1287/mksc.1060.0252

Song, J., Li, F., Wu, D. D., Liang, L., \& Dolgui, A. (2017). Supply Chain Coordination through Integration of Innovation Effort and Advertising Support. Applied Mathematical Modelling, 49, 108-123. https://doi.org/10.1016/j.apm.2017.04.041

Taylor, T. A. (2002). Supply Chain Coordination under Channel Rebates with Sales Effort Effects. Management Science, 48, 992-1007. https://doi.org/10.1287/mnsc.48.8.992.168

Tsay, A. A., \& Agrawal, N. (2000). Channel Dynamics under Price and Service Competition. Manufacturing and Service Operations Management, 2, 372-391. https://doi.org/10.1287/msom.2.4.372.12342

Wang, Y., \& Gerchak, Y. (2001). Supply Chain Coordination When Demand Is Shelf-Space Dependent. Manufacturing \& Service Operations Management, 3, 82-87. https://doi.org/10.1287/msom.3.1.82.9998

Xiao, T. J., Yu, G., Sheng, Z. H., \& Xia, Y. S. (2005). Coordination of a Supply Chain with One Manufacturer and Two-Retailers under Demand Promotion and Disruption Management Decisions. Annals of Operations Research, 135, 87-109. https://doi.org/10.1007/s10479-005-6236-6

Xiao, T., Luo, J., \& Jin, J. (2009). Coordination of a Supply Chain with Demand Stimulation and Random Demand Disruption. International Journal of Information Systems and Supply Chain Management, 2, 1-15. https://doi.org/10.4018/jisscm.2009010101

Xie, J. P., Liang, L., Liu, L. H., \& Ieromonachou, P. (2017). Coordination Contracts of Dual Channel with Cooperation Advertising in Closed-Loop Supply Chains. Interna- 
tional Journal of Production Economics, 183, 528-538.

https://doi.org/10.1016/j.ijpe.2016.07.026

Xu, G. Y., Dan, B., Zhang, X. M., \& Liu, C. (2014). Coordinating a Dual-Channel Supply Chain with Risk-Averse under a Two-Way Revenue Sharing Contract. International Journal of Production Economics, 147, 171-179. https://doi.org/10.1016/j.ijpe.2013.09.012

Yan, R., \& Pei, Z. (2018). Return Policies and O2O Coordination in the e-Tailing Age. Journal of Retailing and Consumer Services, 50, 314-321. https://doi.org/10.1016/j.jretconser.2018.07.006

Zhou, Y. W., Guo, J. S., \& Zhou, W. H. (2018). Pricing/Service Strategies for a Dual-Channel Supply Chain with Free Riding and Service-Cost Sharing. International Journal of Production Economics, 196, 198-210. https://doi.org/10.1016/j.ijpe.2017.11.014 